\title{
Dopamine transporter blockade increases LTP in the CA1 region of the rat hippocampus via activation of the D3 dopamine receptor
}

\author{
Jarod Swant ${ }^{1}$ and John J. Wagner ${ }^{2,3}$ \\ ${ }^{1}$ Department of Pharmaceutical Sciences, North Dakota State University, Fargo, North Dakota 58105, USA; ${ }^{2}$ Department of \\ Physiology \& Pharmacology, University of Georgia, Athens, Georgia 30602, USA
}

\begin{abstract}
Dopamine has been demonstrated to be involved in the modulation of long-term potentiation (LTP) in the CAl region of the hippocampus. As monoamine transporter blockade will increase the actions of endogenous monoamine neurotransmitters, the effect of a dopamine transporter (DAT) antagonist on LTP was assessed using field excitatory postsynaptic potentials recorded in the CAl region of the rat hippocampal slice preparation. Application of the DAT-specific blocker GBR 12,935 produced a significant enhancement in LTP of Schaffer collateral synapses in the CAl at concentrations as low as $100 \mathrm{nM}$. A selective DI/D5 dopamine receptor antagonist $(\mathrm{SCH} 23,390,1 \mu \mathrm{M})$ did not affect the ability of GBR 12,935 to enhance LTP, whereas application of the D3 dopamine receptor antagonist U 99,194 (1 $\mu \mathrm{M})$ blocked the GBR 12,935-induced enhancement in LTP. In addition, a D3 dopamine receptor agonist (7-OH-DPAT, $1 \mu \mathrm{M})$ caused a significant increase in LTP, an effect that was also blocked by $\mathrm{U}$ 99,194 (3 $\mu \mathrm{M})$. These results suggest that either endogenously released dopamine (facilitated by DAT blockade) or exogenously applied dopamine agonist can act to increase LTP in the CAl of the hippocampus via activation of the D3 subtype of dopamine receptor.
\end{abstract}

Long-term potentiation (LTP) is a long-lasting increase in synaptic strength that can be induced by high-frequency electrical stimulation (HFS) (Bliss and Lomo 1973). In the CA1 region of the hippocampus, LTP can be modulated by several neurotransmitters, including dopamine (Frey et al. 1990). The modulation of hippocampal CA1 synaptic plasticity through activation of dopaminergic receptors may be considered somewhat surprising, given that the concentration of dopamine (DA) in this area is quite low relative to the other monoamine neurotransmitters (Bjorklund and Lindvall 1978; Verhage et al. 1992). Despite its low concentration in the hippocampus (or perhaps because of it), the modulation of hippocampal synaptic plasticity by DA remains an interesting phenomenon that has yet to be fully characterized.

In hippocampal slices, the effects of exogenously applied dopamine receptor agonists/antagonists on LTP in the CA1 have been studied by several investigators. For instance, the application of dopamine D1/D5 agonists results in an increase in the magnitude of LTP (Otmakhova and Lisman 1996), while application of the D1/D5 antagonist SCH 23,390 results in a decrease in LTP magnitude in both the slice preparation (Frey et al. 1991; Huang and Kandel 1995; Otmakhova and Lisman 1996), as well as in vivo (Swanson-Park et al. 1999). Dopamine agonists also shift the threshold for LTP, in that a weak stimulation that does not normally produce LTP will produce LTP in the presence of a D1 agonist (Li et al. 2003). In comparison, the involvement of D2-like receptors in hippocampal LTP has received relatively little attention. Long-term maintenance of LTP can be prevented by blockade of D2-like receptors (Frey et al. 1990), and we have recently reported that a D2-like antagonist is effective in blocking the facilitory actions of cocaine on LTP magnitude in the CA1 (Thompson et al. 2005). These results indicate that the actions of

\section{${ }^{3}$ Corresponding author.}

E-mail jwagner@vet.uga.edu; fax (706) 542-3015.

Article and publication are at http://www.learnmem.org/cgi/doi/10.1101/ Im.63806. endogenously released DA include the modulation of LTP via D2-like receptor activation.

Endogenous monoamine neurotransmitter actions can be altered by blocking monoamine re-uptake transporters. For example, antagonism of the DAT protein will increase the sphere of influence of DA released into extrasynaptic space from dopaminergic terminals (Cragg and Rice 2004). In contrast, bath application of DA agonists will increase dopaminergic tone throughout the slice, potentially including sites of action typically not relevant for either normal physiological or pathophysiological conditions. Therefore, the application of monoamine re-uptake blockers may have effects that are different from those observed following the bath application of agonists. In regard to their effects on LTP in the CA1 region of the hippocampus, blockade of the norepinephrine transporter (NET) has been shown to have no significant effect on LTP (Thompson et al. 2005), whereas blockade of the serotonin transporter (SERT) tends to decrease LTP (Kojima et al. 2003). As mentioned previously, we have observed an increase in LTP following the application of cocaine (a nonspecific monoamine transporter blocker), and have implicated both the DAT and the D2-like family of dopamine receptors in mediating this effect (Thompson et al. 2005).

In order to characterize the effects of DA re-uptake blockade on LTP in the CA1 region of the hippocampal slice, we have induced several forms of LTP in the presence of the DAT-specific monoamine transporter blocker GBR 12,935. Along its dorsalventral axis, the ventral hippocampus receives the most dopaminergic innervation (Verney et al. 1985), and the ventral CA1 contains more dopamine than the dorsal CA1 (Hortnagl et al. 1991). To maximize the likelihood of observing dopaminemediated effects, horizontal sections were prepared, resulting in the use of slices from the ventral half of the hippocampus in these experiments. Our results show that GBR 12,935 can enhance LTP in a dose-dependent manner that is consistent with actions via DAT blockade, that GBR 12,935 predominantly enhances NMDAR-dependent LTP (nmdaLTP), and that activation 
of the D3 dopamine receptor mediates the LTP-enhancing effects of GBR 12,935 in the CA1 region of the rat hippocampus.

\section{Results}

\section{LTP magnitude is increased by blockade of the dopamine re-uptake transporter}

The field excitatory post-synaptic potential (fEPSP) was measured in the stratum radiatum of the CA1 in response to stimulation of the Schaffer collaterals in all experiments. Comparison of stimulus response curves between control and GBR 12,935-treated slices revealed no significant difference in baseline fEPSP responsiveness (data not shown). GBR 12,935 did not affect the synaptic response, as the fEPSP slope was $98 \% \pm 2 \%$ of the pre-drug baseline after $30 \mathrm{~min}$ of drug application. As shown in Figure $1 \mathrm{~A}$, the normalized magnitude of LTP in control slices 30 min posttetanus was $1.57 \pm 0.05[n=28(14)]$ [all $n$ values are represented in the format " $n=$ number of slices (number of animals)"]. The LTP magnitude 30 min post-tetanus in slices treated with GBR $12,935(1 \mu \mathrm{M})$ was significantly increased to $1.94 \pm 0.11$ $[n=13(8)]$.

Several concentrations of GBR 12,935 were tested for their effects on LTP as shown in Figure 1B. At $10 \mathrm{nM}$, LTP was $1.54 \pm 0.08[n=12(6)] ;$ at $30 \mathrm{nM}$, LTP was $1.79 \pm 0.12$ $[n=10(5)] ;$ at $100 \mathrm{nM}$, LTP was $1.85 \pm 0.13[n=8(4)]$; at $300 \mathrm{nM}$, LTP was $1.91 \pm 0.11[n=8(4)]$; at $3 \mu \mathrm{M}$, LTP was $1.75 \pm 0.06$
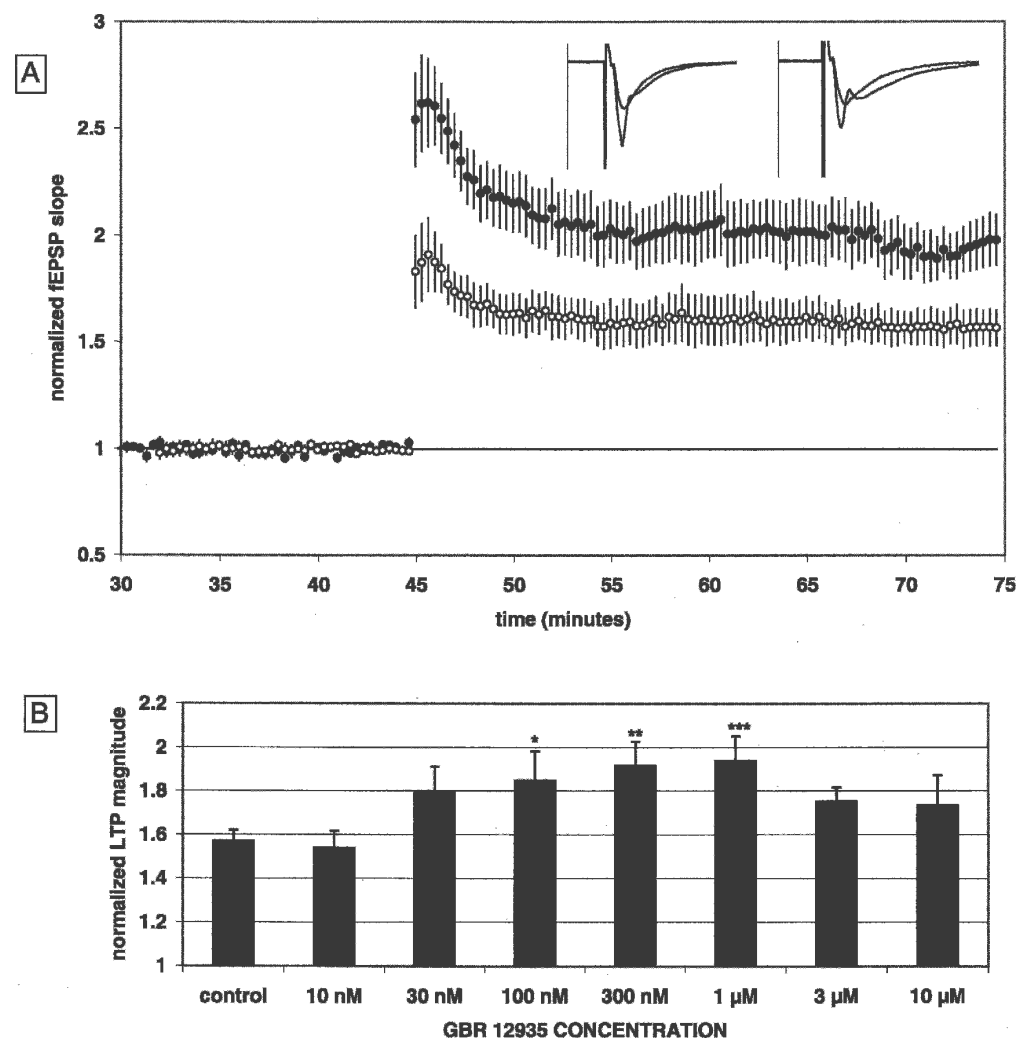

Figure 1. GBR 12,935 enhances LTP in a dose-dependent manner. (A) Summary plot of normalized fEPSP slope measurements recorded in the CA1 region of the hippocampus. The closed circles are from GBR 12,935 $(1 \mu \mathrm{M})$ treated slices; the open circles show results from control slices. Error bars are \pm SEM. Three $(100 \mathrm{~Hz}) /(1 \mathrm{sec})$ stimulus trains separated by $20 \mathrm{sec}$ were used to tetanize the slices at $t=45 \mathrm{~min}$. Insets are 50-msec sweeps taken from representative experiments illustrating the average fEPSP 0-5 min prior to and 25-30 min post-tetanus (the vertical scale bar is $3.5 \mathrm{mV}$ ). The left pair of sweeps is from a GBR 12,935-treated slice; the right pair is from a non-drug, control slice. (B) Summary quantification of the dose response for the effect of GBR 12,935 on LTP against control; ${ }^{*} P<0.05$; ${ }^{* \star} P<0.01 ;{ }^{* * *} P<0.001$. Bars are the mean \pm SEM. $[n=8(4)]$; and at $10 \mu \mathrm{M}$, LTP was $1.73 \pm 0.14[n=8(4)]$ (Fig. 1B). GBR 12,935 significantly enhanced LTP at concentrations of 100 $\mathrm{nM}(P<0.05), 300 \mathrm{nM}(P<0.01)$, and $1 \mu \mathrm{M}(P<0.001)$. The dose urve for GBR 12,935 provides evidence that the increased LTP documented here is mediated by the DAT protein, since $100 \mathrm{nM}$ is approximately one-half the value of GBR 12,935 enhancement of LTP by the blockade of the DAT protein is conprior results, which also suggested that NET and/ or SERT blockade is not sufficient for the cocaine-induced enhancement of LTP in the CA1 (Thompson et al. 2005). tentially induce LTP through two distinct routes of calcium inMDARs), or voltage-dependent calcium channels (VDCCs) can to induction of LTP (Collingridge et al. 1983; Grover and Teyler 1990). LTP induced by activation via either NMDARs or VDCC channels can be pharmacologically isolated and the resulting isolated LTP is termed either nmdaLTP or nmdaLTP is enhanced by GBR 12,935

In order to further characterize the effect of DAT blockade on synaptic plasticity, we isolated LTP induced by the NMDA receptor by blocking voltage-dependent calcium channels with nifedipine (nmdaLTP). LTP was induced by three $100-\mathrm{Hz}$ trains of 1 sec duration delivered at 20 -sec intervals. When nifedipine $(25 \mu \mathrm{M})$ was added $30 \mathrm{~min}$ pre-tetanus, a control nmdaLTP magnitude of $1.60 \pm 0.07$ $[n=13(6)]$ resulted (Fig. 2). Since the magnitude of nmdaLTP was similar to the amount of LTP found in drug-free control slices (Fig. 1), we conclude that voltage-dependent calcium channel LTP (vdccLTP) was not a significant component of the LTP induced using our standard induction protocol. When GBR $12,935(1 \mu \mathrm{M})$ was tested in slices pretreated with nifedipine $(25 \mu \mathrm{M})$, a significant increase in the magnitude of nmdaLTP to $1.89 \pm 0.09[n=14(5)$; $P<0.05]$ was observed (Fig. 2).

\section{vdccLTP is not affected by GBR 12,935}

We also isolated LTP induced by voltagedependent calcium channels by blocking NMDA receptors with DL-2-amino5-phosphono-pentanoic acid (D-APV) and delivering a high-frequency stimulation protocol as previously described (Grover and Teyler 1990). vdccLTP was induced in the presence of D-APV (50 $\mu \mathrm{M}$ ) using four $200-\mathrm{Hz}$ trains of $0.5 \mathrm{sec}$ duration separated by 20 -sec intervals. The vdccLTP magnitude $30 \mathrm{~min}$ posttetanus in control slices was $1.22 \pm 0.06$ $[n=10(4)]$ (Fig. 3 ). The addition of GBR 12,935 to D-APV $(50 \mu \mathrm{M})$ treated slices did not significantly alter vdccLTP, as the magnitude of vdccLTP in the presence of GBR 12,935 (1 $\mu \mathrm{M})$ was $1.23 \pm 0.07[n=10(4)]$ (Fig. 3). Taken together, our results with nmdaLTP and 


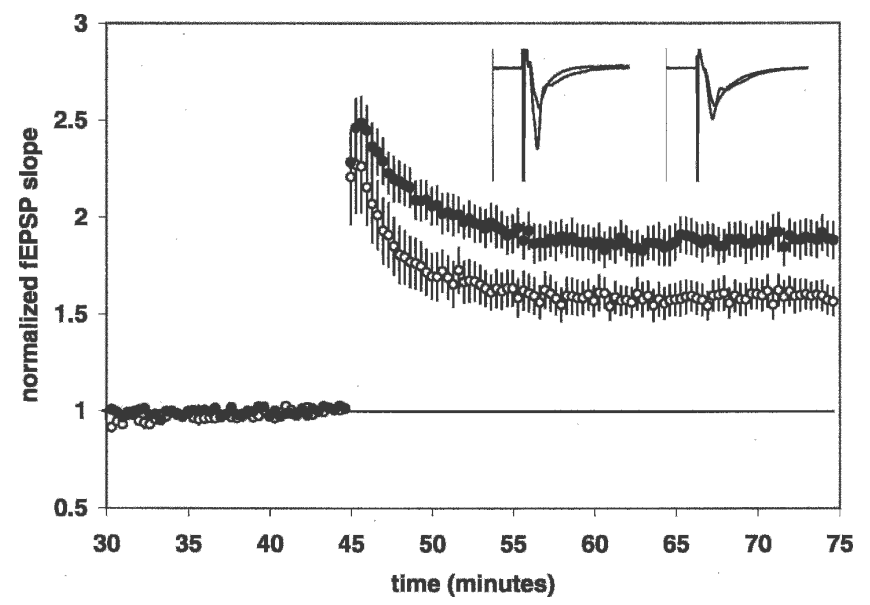

Figure 2. GBR 12,935 enhances nmdaLTP. Summary plot of normalized fEPSP slope measurements recorded in the presence of the VDCC antagonist nifedipine $(25 \mu \mathrm{M})$. The closed circles are results obtained from nifedipine + GBR 12,935-treated slices; the open circles show results from nifedipine-alone treated slices. Error bars are \pm SEM. Three $(100$ $\mathrm{Hz}) /(1 \mathrm{sec})$ stimulus trains separated by $20 \mathrm{sec}$ were used to tetanize the slices at $45 \mathrm{~min}$. Insets are 50-msec sweeps taken from representative experiments illustrating the average fEPSP $0-5$ min prior to and $25-30$ min post-tetanus (the vertical scale bar is $3.5 \mathrm{mV}$ ). The left pair of sweeps is from a nifedipine + GBR 12,935-treated slice; the right pair is from a Nifedipine-alone treated slice.

vdccLTP imply that the facilitation of LTP by GBR 12,935 is dependent on the activation of NMDA receptors during tetanization.

\section{LTP of the NMDAR response is not affected by GBR 12,935}

Under normal conditions, LTP induction by activation of NMDA receptors can result in an increase of both the AMPA and NMDA receptor-mediated components of synaptic transmission (Clark

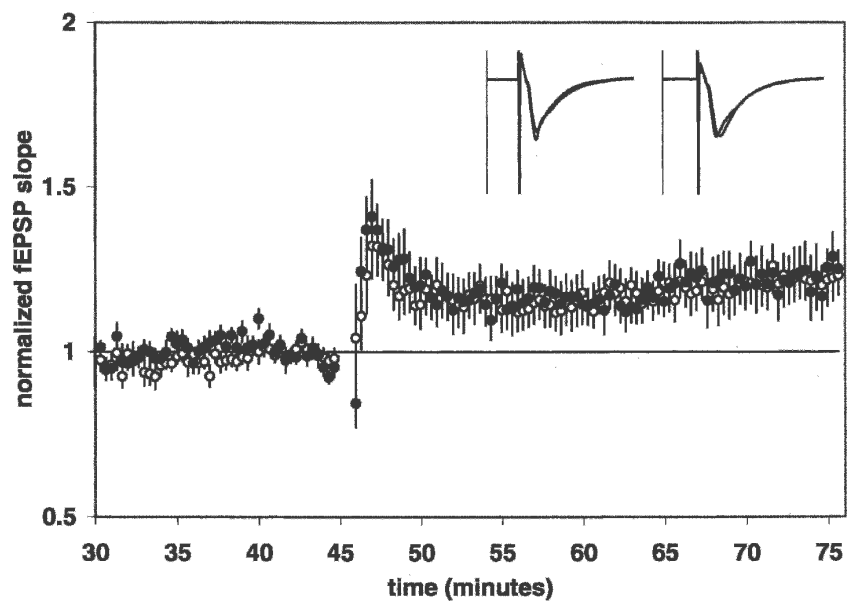

Figure 3. GBR 12,935 does not affect vdccLTP. Summary plot of normalized fEPSP slope measurements recorded in the presence of the NMDAR antagonist D-APV $(50 \mu \mathrm{M})$. The closed circles are results obtained from D-APV + GBR 12,935-treated slices; the open circles show results from D-APV-alone treated slices. Error bars are \pm SEM. Four $200-\mathrm{Hz}, 0.5 \mathrm{sec}$ duration trains at double stimulus intensity separated by $5 \mathrm{sec}$ were used to tetanize the slices at $45 \mathrm{~min}$. Insets are 50-msec sweeps taken from representative experiments illustrating the average fEPSP $0-5$ min prior to and 25-30 min post-tetanus (the vertical scale bar is $2.5 \mathrm{mV}$ ). The left pair of sweeps is from a D-APV + GBR 12,935-treated slice; the right pair is from a D-APV-alone treated slice. and Collingridge 1995). Isolated NMDA receptor-mediated synaptic responses can also undergo LTP (Bashir et al. 1991). To test the effect of GBR 12,935 on isolated NMDA receptor-mediated synaptic responses, we used a perfusion aCSF containing $10 \mu \mathrm{M}$ 6,7-dinitroquinoxaline-2,3(1H, 4H)-dione (DNQX) to block AMPA receptors and low $(0.1 \mathrm{mM}) \mathrm{MgCl}_{2}$ to minimize $\mathrm{Mg}^{2+}$ blockade of NMDA receptors. Nifedipine $(25 \mu \mathrm{M})$ was also present to block voltage-dependent calcium channels. Under these conditions, the control LTP magnitude of the NMDA receptormediated response (NMDAR response) was $1.20 \pm 0.05$ $[n=12(6)]$ (Fig. 4). In the presence of GBR 12,935 (1 $\mu \mathrm{M})$, LTP of the NMDAR response was $1.27 \pm 0.11[n=12(6)]$ (Fig. 4$)$. Thus LTP of the NMDAR response at 30 min post-tetanus was not significantly altered by GBR 12,935 . The potentiated synaptic responses we measured in the presence of low $\mathrm{Mg}^{2+}$ and DNQX/ nifedipine were primarily NMDAR mediated; as they were completely blocked (>97\%) by $50 \mu \mathrm{M}$ D-APV added 30 min posttetanus (see insets in Figure 4 for representative examples).

\section{The LTP-enhancing effect of GBR 12,935 $(1 \mu \mathrm{M})$ is blocked by a D3 antagonist, not by a D1/D5 antagonist}

The effects of GBR 12,935 on LTP could be mediated by any of the dopamine receptor subtypes. To further elucidate the mechanism of GBR 12,935 on LTP, either a D1/D5 antagonist (SCH 23,390 ) or a D3 antagonist (U 99,194) was applied 30 min prior to GBR 12,935. The addition of the D1/D5 antagonist SCH 23,390 did not significantly alter GBR 12,935 's effect on LTP. The LTP magnitude in the presence of both SCH 23,390 $(1 \mu \mathrm{M})$ and GBR $12,935(1 \mu \mathrm{M})$ was significantly enhanced to $1.90 \pm 0.14$ $[n=12(6) ; P<0.05]$ (Fig. 5A). In contrast, the D3 antagonist $\mathrm{U}$ 99,194 blocked the effect of GBR 12,935 on LTP. The LTP magnitude in the presence of both $\mathrm{U} 99,194(1 \mu \mathrm{M})$ and GBR 12,935 $(1 \mu \mathrm{M})$ was $1.58 \pm 0.08[n=10(3)]$ (Fig. $5 \mathrm{~A})$. This antagonistic effect was not due to U 99,194 causing an overall decrease in LTP, since slices treated with U 99,194 alone had an LTP magnitude of

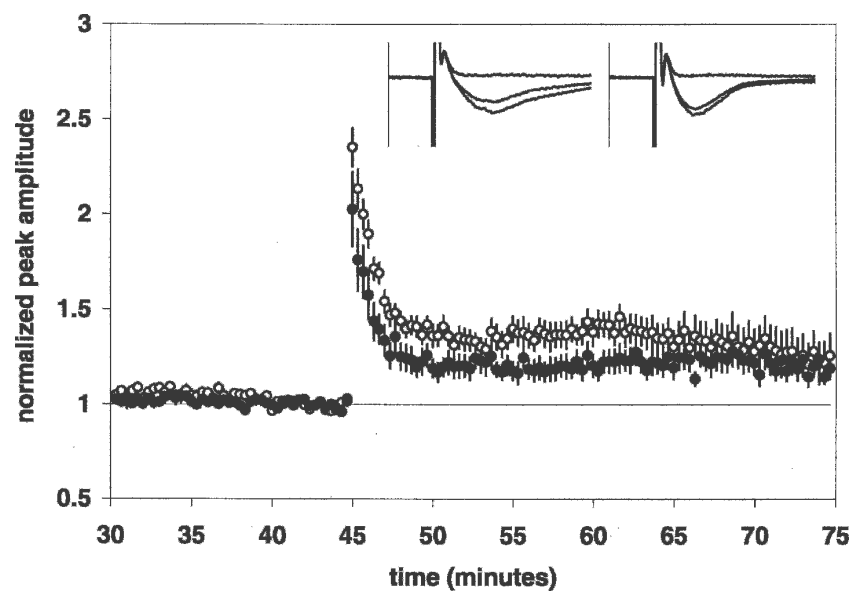

Figure 4. GBR 12,935 does not affect LTP of the NMDAR response. Summary plot of normalized fEPSP peak amplitude measurements recorded in the presence of the AMPAR antagonist DNQX $(10 \mu \mathrm{M})$, low $\mathrm{Mg}^{2+}(0.1 \mathrm{mM})$, and the VDCC antagonist nifedipine $(25 \mu \mathrm{M})$. The closed circles are the results from GBR 12,935-treated slices; the open circles show results from control slices. Error bars are \pm SEM. Three $100-\mathrm{Hz}$ trains separated by $20 \mathrm{sec}$ were used to tetanize the slices at $45 \mathrm{~min}$. Insets are 50-msec sweeps taken from representative experiments illustrating the average fEPSP $0-5$ min prior to, 25-30 min post-HFS, and 40-45 min post-HFS (50 $\mu$ M D-APV added at 30 min post-HFS). The vertical scale bar is $1.5 \mathrm{mV}$. The left set of sweeps is from a DNQX/nifedipine + GBR 12,935-treated slice; the right set is from a DNQX/nifedipine-alone treated slice. 

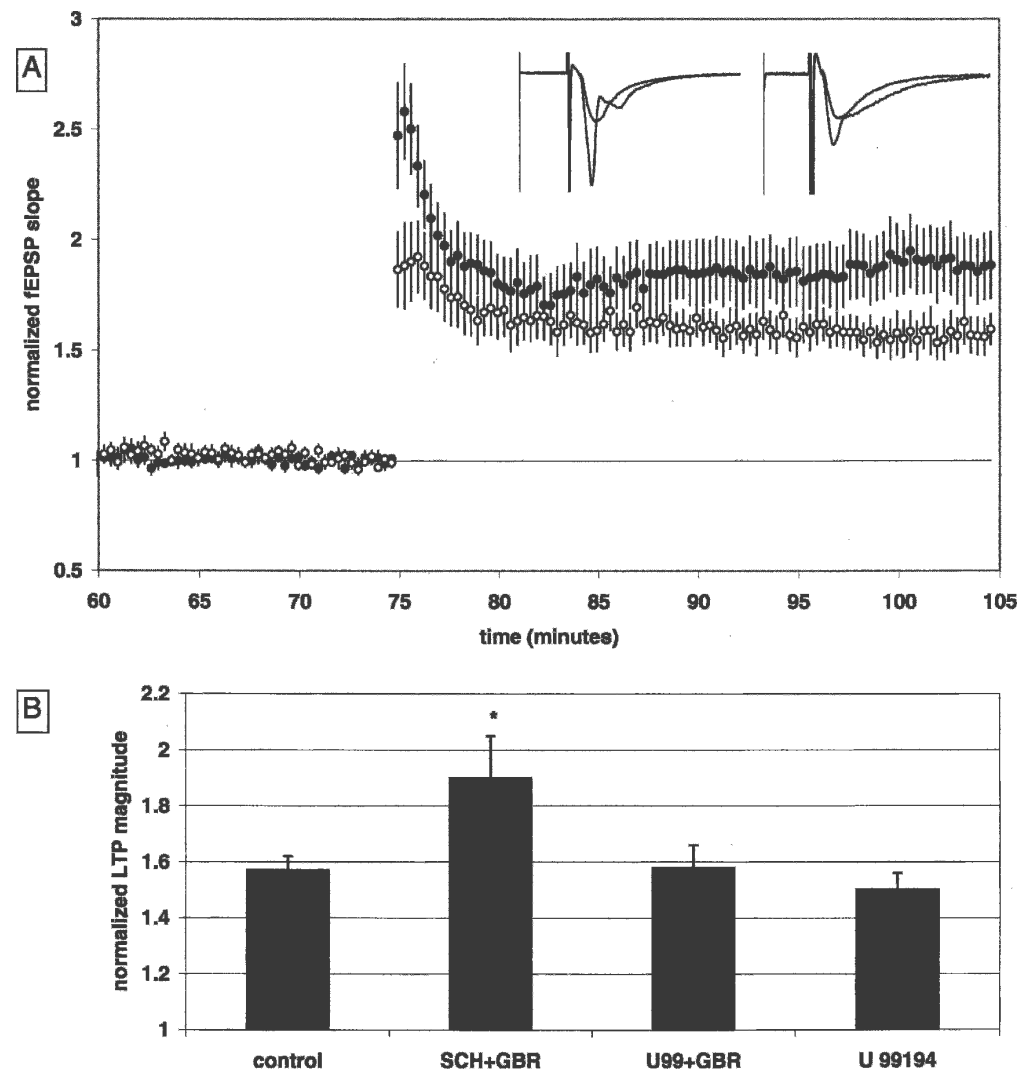

Figure 5. The enhancement of LTP by GBR 12,935 is prevented by a D3 antagonist. (A) Summary plot of normalized fEPSP slope measurements recorded in the CA1 region of the hippocampus. The closed circles are from SCH 23,390 + GBR 12,935 $(1 \mu \mathrm{M}+1 \mu \mathrm{M})$ treated slices; the open circles show results from $U$ 99,194 + GBR 12,935 $(1 \mu \mathrm{M}+1 \mu \mathrm{M})$ treated slices. Error bars are \pm SEM. Three $(100$ $\mathrm{Hz}) /(1 \mathrm{sec})$ stimulus trains separated by $20 \mathrm{sec}$ were used to tetanize the slices at $t=75 \mathrm{~min}$. Insets are 50-msec sweeps taken from representative experiments illustrating the average fEPSP $0-5$ min prior to and $25-30$ min post-HFS (the vertical scale bar is $3.5 \mathrm{mV}$ ). The left pair of sweeps is from a SCH 23,390 + GBR 12,935-treated slice; the right pair is from a U 99,194 + GBR 12,935-treated slice. (B) Summary quantification of drug effects on LTP. LTP at 30 min post-tetanus is significantly enhanced in slices treated with SCH 23,390 + GBR 12,935 as compared to the U 99,194 + GBR 12,935-treated slices; ${ }^{*} P<0.05$ (control data from Fig. 1B are illustrated for comparison).

$1.50 \pm 0.06[n=14(4)]$ (Fig. 5B), which was not significantly different from drug-free control values.

\section{A D3 agonist increases LTP, an effect prevented by pre-incubation with a D3 antagonist}

The finding that the LTP-enhancing effects of GBR 12,935 are blocked by a D3 receptor antagonist led us to test the prediction that a bath-applied D3 agonist would also increase LTP. The D3 dopamine receptor agonist 7-OH-DPAT did not affect the baseline synaptic responses, as baseline pre-drug fEPSP slopes were $101 \% \pm 4 \%$ of the baseline after 30 min of drug application. The LTP magnitude was significantly increased in the presence of 7-OH-DPAT $(1 \mu \mathrm{M})$ to $1.88 \pm 0.06[n=13(6) ; P<0.01]$ (Fig. 6B) when compared to drug-free controls, and this effect was blocked by pre-application of the D3 dopamine receptor antagonist $U$ 99,194 $(3 \mu \mathrm{M})$. The LTP magnitude in the presence of both drugs was $1.60 \pm 0.04[n=16(5)]$, a value that is significantly different from 7-OH-DPAT-treated slices $(P<0.01)$ (Fig. 6B), and is not significantly different from the control group.

\section{Discussion}

We have studied the effects of dopamine transporter blockade on several different forms of LTP in the CA1 region of the hippo- campus. Our main finding is that the monoamine transporter blocker GBR 12,935 , a selective dopamine transporter antagonist, enhances LTP at Schaffer collateral synapses in stratum radiatum through activation of dopaminergic D3 receptors. GBR 12,935 was chosen for this study because it is at least 10 -fold more selective for DAT over NET or SERT. GBR 12,935 significantly increased LTP induced by a strong tetanus protocol at a concentration as low as 100 nM, suggesting that GBR 12,935 increases LTP by interaction with the DAT $\left(K_{\mathrm{i}}[\mathrm{nM}]\right.$ for DAT, NET, SERT: 21,225 , 6514, respectively) (Torres et al. 2003). Previous results from our laboratory have also shown that cocaine enhances LTP in the CA1 of the hippocampus through blockade of the DAT (Thompson et al. 2005).

Grover and Teyler (1990) have shown that tetanus-evoked LTP in the CA1 can be comprised of both NMDA receptor-dependent and NMDA receptor-independent components. Therefore, we were interested in determining if DAT blockade would affect both, or only one of these forms of LTP. Tetanus protocols like the one we used to induce LTP in GBR 12,935 slices (Fig. 1) may induce LTP of which a portion is comprised of nmdaLTP and a smaller portion is vdccLTP (Freir and Herron 2003). The NMDA receptor-dependent component can be isolated by blocking L-type voltage-gated calcium channels, and under these conditions, we found nmdaLTP to be significantly increased in slices treated with GBR 12,935 as compared to controls. If a significant amount of vdccLTP was being induced by our highfrequency protocol, we would expect to see less LTP in control slices tested for nmdaLTP using this same tetanus. This was not the case in our recording conditions, as LTP magnitude was similar under both circumstances (cf. control LTP in Figs. 1 and 2).

We also examined NMDA receptor-independent LTP, and based on the absence of effect of nifedipine on the magnitude of LTP noted above, it is unlikely that our three-train tetanus protocol induced any significant amount of vdccLTP. Therefore, we used a strong tetanus protocol (four $200-\mathrm{Hz}$ trains of $0.5 \mathrm{sec}$ duration separated by a 20 -sec interval at $2 \times$ baseline stimulus intensity) previously shown to induce vdccLTP (Grover and Teyler 1990). vdccLTP was induced in the presence of D-APV, both with and without GBR 12,935. Under these conditions, vdccLTP was not significantly affected by GBR 12,935 . Taken together, our results concerning nmdaLTP and vdccLTP imply that the facilitation of LTP by GBR 12,935 is dependent on the activation of NMDA receptors during tetanization.

The fEPSP in the CA1 consists of both an AMPA and an NMDA receptor component. The NMDA receptor-mediated response can be pharmacologically isolated by the addition of an AMPA receptor antagonist to a modified perfusion media containing low magnesium. A previous report using a theta stimulation tetanus protocol did not find a great amount of LTP of the 

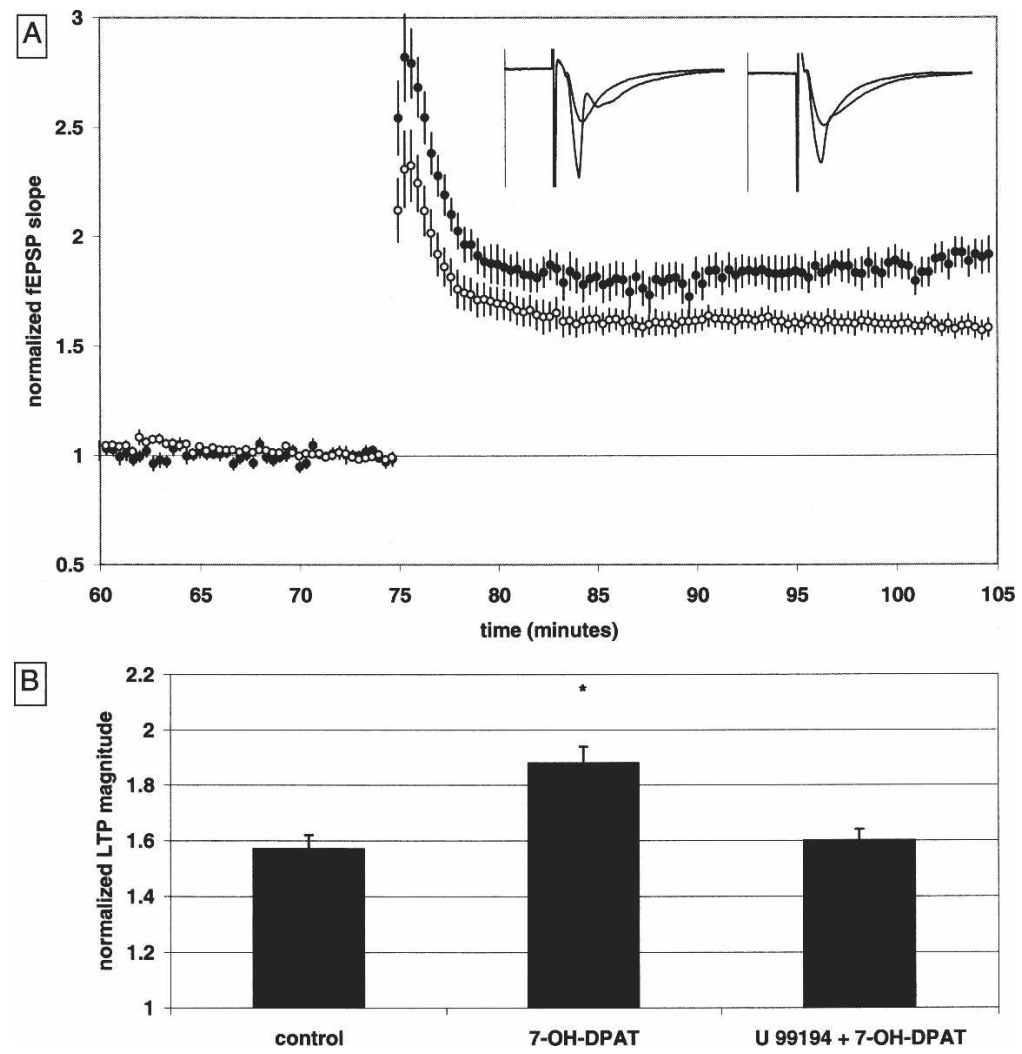

Figure 6. 7-OH-DPAT enhances LTP, an effect that is prevented by a D3 antagonist. (A) Summary plot of normalized fEPSP slope measurements recorded in the CA1 region of the hippocampus. The closed circles are from 7-OH-DPAT $(1 \mu \mathrm{M})$ treated slices; the open circles show results from U 99,194 $+7-\mathrm{OH}-\mathrm{DPAT}(3 \mu \mathrm{M}+1 \mu \mathrm{M})$ treated slices. Error bars are \pm SEM. Three $(100 \mathrm{~Hz}) /(1 \mathrm{sec})$ stimulus trains separated by $20 \mathrm{sec}$ were used to tetanize the slices at $t=75 \mathrm{~min}$. Insets are 50 -msec sweeps taken from representative experiments illustrating the average fEPSP $0-5$ min prior to and $25-30$ min post-HFS (the vertical scale bar is $3.5 \mathrm{mV}$ ). The left pair of sweeps is from a 7-OH-DPAT-treated slice; the right pair is from a U 99,194 + 7-OH-DPAT-treated slice. (B) Summary quantification of drug effects on LTP. LTP at 30 min post-tetanus is significantly enhanced in slices treated with 7-OH-DPAT as compared to the U 99,194 + 7-OH-DPAT-treated slices; ${ }^{*} P<0.05$ (control data from Fig. $1 \mathrm{~B}$ are illustrated for comparison).

NMDAR response (Kauer et al. 1988; Muller and Lynch 1988), whereas others have found that isolated NMDA receptormediated synaptic responses can undergo LTP (Bashir et al. 1991; Xie et al. 1992). Under our conditions, we observed a modest amount of potentiation of the NMDAR synaptic response, and GBR 12,935 did not enhance this form of LTP, indicating that AMPAR participation is required to observe the effects of DAT blockade on LTP.

As previously mentioned, bath application of dopamine D1/ D5 agonists during tetanus results in an increase in the magnitude of LTP (Otmakhova and Lisman 1996), whereas the activation of D2-like dopamine receptors is responsible for cocaine's LTP-enhancing effect (Thompson et al. 2005). More recently, we have found that D3 dopaminergic receptor antagonists can block a cocaine-induced decrease in the evoked IPSCs in the CA1 (Hammad and Wagner 2006), an effect that could contribute to the increase in LTP we have observed here in the presence of GBR 12,935 . Therefore, we tested both a D1/D5 dopamine receptor antagonist (SCH 23,390), and a D3 dopamine receptor antagonist (U 99,194), to further characterize the mechanism underlying the effect of GBR 12,935 on LTP. Although SCH 23,390 did not alter the ability of GBR 12,935 to increase LTP, U 99,194 did block the ability of GBR 12,935 to enhance LTP, suggesting that dopaminergic D3 receptors mediate the consequences of DAT blockade. The prevention of the LTPenhancing effects of GBR 12,935 by a D3 antagonist led us to investigate the effects of a D3 agonist on LTP. The D3 dopamine agonist 7-OH-DPAT significantly increased LTP magnitude, an effect that was also blocked by U 99,194.

Given the aforementioned finding that there is not much dopamine present in the hippocampus (Bjorklund and Lindvall 1978; Verhage et al. 1992), it may be important that dopamine has a higher affinity for the D3 receptor than the other dopamine receptor subtypes (Sokoloff et al. 1990). This could be crucial for the D3 receptor-mediated increase in LTP we have observed, as it is possible that the actions of endogenously released dopamine caused by DAT blockade increase the concentration of dopamine enough to activate D3 receptors, while it may not be enough to activate significant numbers of other dopamine receptor subtypes. Dopamine D3 receptors have been shown to inhibit adenylyl cyclase (Chio et al. 1994), an action that is incongruent with our results at first glance, as inhibition of adenylyl cyclase decreases early LTP (Otmakhova et al. 2000). However, if a D3mediated decrease in the IPSCs evoked from the stratum radiatum were to occur (Hammad and Wagner 2006), one possible explanation for the apparent discrepancy is that endogenously released dopamine acts through D3 receptors located on a subset of inhibitory interneurons in the CA1, leading to an increase in LTP via disinhibition.

In regard to its functional role, dopamine in the hippocampus may act to increase the storage of information into memory in the presence of novel stimuli (Lisman and Grace 2005). Placing a rat in a novel cage causes a significant increase of dopamine release in the hippocampus (Ihalainen et al. 1999). Not only does novelty increase dopamine in the hippocampus, this dopamine release apparently modulates LTP. Li et al. (2003) have demonstrated that a weak tetanus to the Schaffer collateral input to CA1 failed to evoke LTP in rats placed in a familiar cage, but when the animal is placed in a novel cage, the same weak tetanus induces a robust LTP, an effect blocked by a D1 antagonist. Our findings outline an additional possible contributing mechanism of action for the increase in LTP caused by exposure to novelty-the activation of D3 receptors by endogenously released dopamine.

In conclusion, we have tested the effects of GBR 12,935, a DAT selective monoamine transporter blocker, on several forms of synaptic plasticity in the CA1 of the rat hippocampus. Our results demonstrate that endogenously released dopamine (facilitated by DAT blockade) or exogenously applied dopamine agonist can act to increase LTP, and that this increase is mediated via the activation of the D3 subtype of dopamine receptor. This D3mediated action represents a distinct, yet complementary effect in addition to the previously described D1 receptor mechanism by which dopamine can act to facilitate LTP in the CA1 region of the hippocampus. 


\section{Materials and Methods}

\section{Slice preparation}

Freshly prepared hippocampal slices $(500 \mu \mathrm{m})$ were obtained from 200-300-g male Sprague-Dawley rats (Harlan) that had been anesthetized (Halothane) prior to decapitation. Horizontally cut slices were dissected in ice-cold, oxygenated $\left(95 \% \mathrm{O}_{2} / 5 \% \mathrm{CO}_{2}\right)$ dissection artificial cerebrospinal fluid (aCSF) containing 120 $\mathrm{mM} \mathrm{NaCl}, 3 \mathrm{mM} \mathrm{KCl}, 4 \mathrm{mM} \mathrm{MgCl}, 1 \mathrm{mM} \mathrm{NaH}_{2} \mathrm{PO}_{4}, 26 \mathrm{mM}$ $\mathrm{NaHCO}_{3}$, and $10 \mathrm{mM}$ glucose. The CA3 was surgically removed from all slices. Slices recovered for $1 \mathrm{~h}$ in an oxygenated interface holding chamber with standard aCSF containing $120 \mathrm{mM} \mathrm{NaCl}$, $3 \mathrm{mM} \mathrm{KCl}, 1.5 \mathrm{mM} \mathrm{MgCl}_{2}, 1 \mathrm{mM} \mathrm{NaH} \mathrm{PO}_{4}, 2.5 \mathrm{mM} \mathrm{CaCl}_{2}, 26$ $\mathrm{mM} \mathrm{NaHCO}$, and $10 \mathrm{mM}$ glucose. Slices were then transferred to a submerged recording chamber and recovered for an additional hour at $30^{\circ} \mathrm{C}$ with continuously perfused standard aCSF saturated with $95 \% \mathrm{O}_{2} / 5 \% \mathrm{CO}_{2}$ at $\sim 1 \mathrm{~mL} / \mathrm{min}$ before experiments were begun.

\section{Extracellular recording}

Extracellular recording electrodes ( $\sim \mu \mathrm{m}$ tip) filled with standard aCSF were placed in the stratum radiatum of CA1. Field excitatory post-synaptic potential (fEPSP) responses were evoked with a bipolar stimulating electrode (Kopf instruments) placed on either the CA3 or the subicular side of the recording electrode in the stratum radiatum. Stimulus pulses consisted of a single square wave of $300 \mu \mathrm{sec}$ duration delivered at 30-125 $\mu \mathrm{A}$.

\section{Data acquisition and analysis}

Data were digitized at $10 \mathrm{kHz}$, low pass filtered at $1 \mathrm{kHz}$, and analyzed with pCLAMP9.2 software (Axon Instruments). The initial slope of the population fEPSP was measured by fitting a straight line to the first millisecond of the fEPSP immediately following the fiber volley. Stimulus response curves were performed at the beginning of each experiment. Acceptable fEPSP responses reached a $-0.7 \mathrm{mV} / \mathrm{msec}$ or greater maximum slope. Baseline stimulation pulses of an intensity that gave $40 \%-60 \%$ of the maximum response were given at a frequency of $0.05 \mathrm{~Hz}$ for the entire length of the experiment. Synaptic responses were normalized by dividing all slopes by the average of the 15 fEPSP slopes 5 min pre-tetanus. LTP was defined as the average of the 15 fEPSP responses 25-30 min post-tetanus for all experiments. The peak negative amplitude was used to quantify the NMDAR response in place of the fEPSP slope measure (Fig. 4). A two-tailed unpaired $t$-test was used for statistical comparisons of mean fEPSP slopes. The GBR 12,935 dose response curve was analyzed using one-way ANOVA and Bonferroni post hoc tests.

\section{Drug application}

GBR 12,935, SCH 23,390, 7-OH-DPAT, D-APV, DNQX, and nifedipine were purchased from Sigma; U 99,194 was acquired from Tocris. All drugs were dissolved in standard aCSF for dilution to the desired concentration during experiments. All experiments were monitored drug-free for at least $15 \mathrm{~min}$ to measure potential drug effects on baseline fEPSP responses. Experiments in which no drugs were used were then tetanized at $t=15 \mathrm{~min}$. In experiments using one drug, it was added at $t=15 \mathrm{~min}$; tetanus occurred at $t=45 \mathrm{~min}$. In experiments using two drugs, the first was added at $t=15 \mathrm{~min}$, the second at $t=45 \mathrm{~min}$, with tetanus occurring at $t=75 \mathrm{~min}$. All drugs, once added, were maintained throughout the experiment. In figures depicting two experiments, the tetanus points have been aligned as necessary for ease of comparison.

\section{LTP induction}

The LTP tetanus protocol consisted of three $100-\mathrm{Hz}$ trains of $1 \mathrm{sec}$ duration separated by a 20 -sec interval for all experiments except the vdccLTP experiment depicted in Figure 3. vdccLTP was induced by four $200-\mathrm{Hz}$ trains of $0.5 \mathrm{sec}$ duration separated by a 5 -sec interval. vdccLTP stimulus strength during the tetanus train was either double baseline stimulus intensity (in microamperes) for 12 of the 20 vdccLTP slices or double the slope (in millivolts per millisecond) value for the remaining eight vdccLTP slices. The means for these groups were similar, and the data was pooled.

\section{Acknowledgments}

J.J.W. was funded by the National Institute on Drug Abuse (DA16302).

\section{References}

Bashir, Z., Alford, S., Davies, S.N., Randall, A.D., and Collingridge, G.L. 1991. Long-term potentiation of NMDA receptor-mediated synaptic transmission in the hippocampus. Nature 349: 156-158.

Bjorklund, A. and Lindvall, O. 1978. The mesotelencephalic dopamine neuron system: A review of its anatomy. In Limbic mechanisms (eds. E. Livingstone and O. Hornykiewicz), pp. 307-321. Plenum Press, New York.

Bliss, T.V. and Lomo, T. 1973. Long-lasting potentiation of synaptic transmission in the dentate area of the anaesthetized rabbit following stimulation of the perforant path. I. Physiol. 232: 331-356.

Chio, C., Lajiness, M.E., and Huff, R.M. 1994. Activation of heterologously expressed $\mathrm{D}_{3}$ dopamine receptors: Comparison with $\mathrm{D}_{2}$ dopamine receptors. Mol. Pharmacol. 45: 51-60.

Clark, K.A. and Collingridge, G.L. 1995. Synaptic potentiation of dual-component excitatory postsynaptic currents in the rat hippocampus. J. Physiol. 482: 39-52.

Collingridge, G.L., Kehl, S.J., and McLennan, H. 1983. Excitatory amino acids in synaptic transmission in the Schafer collateral-commissural pathway of the rat hippocampus. J. Physiol. 334: 33-46.

Cragg, S.J. and Rice, M.E. 2004. Dancing past the DAT at a DA synapse. Trends Neurosci. 27: 270-277.

Freir, D.B. and Herron, C.E. 2003. Inhibition of L-type voltage dependent calcium channels causes impairment of long-term potentiation in the hippocampal CA1 region in vivo. Brain Res. 967: $27-36$

Frey, U., Schroeder, H., and Matthies, H. 1990. Dopaminergic antagonists prevent long-term maintenance of posttetanic LTP in the CA1 region of rat hippocampal slices. Brain Res. 522: 69-75.

Frey, U., Matthies, H., and Reymann, K.G. 1991. The effect of dopaminergic D1 receptor blockade during tetanization on the expression of long-term potentiation in the rat CA1 region in vitro. Neurosci. Lett. 129: 111-114.

Grover, L.M. and Teyler, T.J. 1990. Two components of long-term potentiation induced by different patterns of afferent activation. Nature 347: 447-449.

Hammad, H. and Wagner, J.J. 2006. Dopamine-mediated disinhibition in the CA1 region of rat hippocampus via D3 receptor activation. $J$. Pharmacol. Exp. Ther. 316: 113-120.

Hortnagl, H., Berger, M.L., Sperk, G., and Pifl, Ch. 1991. Regional heterogeneity in the distribution of neurotransmitter markers in the rat hippocampus. Neuroscience 45: 261-272.

Huang, Y. and Kandel, E.R. 1995. D1/D5 receptor agonists induce a protein synthesis-dependent late potentiation in the CA1 region of the hippocampus. Proc. Natl. Acad. Sci. 92: 2446-2450.

Ihalainen, J.A., Riekkinen, P., and Feenstra, M.G. 1999. Comparison of dopamine and noradrenaline release in mouse prefrontal cortex, striatum and hippocampus using microdialysis. Neurosci. Lett. 277: 71-74

Kauer, J.A., Malenka, R.C., and Nicoll, R.A. 1988. A persistent postsynaptic modification mediates long-term potentiation in the hippocampus. Neuron 1: 911-917.

Kojima, T., Matsumoto, M., Togashi, H., Tachibana, K., Kemmotsu, O., and Yoshioka, M. 2003. Fluvoxamine suppresses the long-term potentiation in the hippocampal CA1 field of anesthetized rats: An effect mediated via 5-HT1A receptors. Brain Res. 959: 165-168.

Li, S., Cullen, W.K., Anwyl, R., and Rowan, M.J. 2003. Dopaminedependent facilitation of LTP induction in hippocampal CA1 by exposure to spatial novelty. Nat. Neurosci. 6: 526-531.

Lisman, J.E. and Grace, A.A. 2005. The hippocampal-VTA loop: Controlling the entry of information into long-term memory. Neuron 46: 703-713.

Muller, D. and Lynch, G. 1988. Long-term potentiation differentially affects two components of synaptic responses in hippocampus. Proc Natl. Acad. Sci. 85: 9346-9350.

Otmakhova, N.A. and Lisman, J.E. 1996. D1/D5 dopamine receptor activation increases the magnitude of early long-term potentiation at CA1 hippocampal synapses. J. Neurosci. 16: 7478-7486.

Otmakhova, N.A., Otmakhov, N., Mortenson, L.H., and Lisman, J.E. 2000. Inhibition of the cAMP pathway decreases early long-term 
potentiation at CA1 hippocampal synapses. J. Neurosci. 20: $4446-4451$.

Sokoloff, P., Giros, B., Martres, M.-P., Bouthenet, M.-L., and Schwarts, J.-C. 1990. Molecular cloning and characterization of a novel dopamine receptor (D3) as a target for neuroleptics. Nature 347: 146-151.

Swanson-Park, J.L., Coussens, C.M., Mason-Parker, S.E., Raymond, C.R., Hargreaves, E.L., Dragunow, M., Cohen, A.S., and Abraham, W.C. 1999. A double dissociation within the hippocampus of dopamine D1/D5 receptor and $\beta$-adrenergic receptor contributions to the persistence of long-term potentiation. Neuroscience 92: 485-497.

Thompson, A.M., Swant, J., and Wagner, J.J. 2005. Cocaine-induced modulation of long-term potentiation in the CA1 region of rat hippocampus. Neuropharmacology 49: 185-194.

Torres, G.E., Gainetdinov, R.R., and Caron, M.G. 2003. Plasma membrane monoamine transporters: Structure, regulation and function. Nat. Rev. Neurosci. 4: 13-25.

Verhage, M., Ghijsen, W., Boomsma, F., and Lopes de silva, F. 1992. Endogenous noradrenaline and dopamine in nerve terminals of the hippocampus: Differences in levels and release kinetics. J. Neurochem. 53: $881-887$.

Verney, C., Baulac, M., Berger, B., Alvarez, C., Vigny, A., and Helle, K.B. 1985. Morphological evidence for a dopaminergic terminal field in the hippocampal formation of young and adult rat. Neuroscience 14: 1039-1052.

Xie, X., Berger, T.W., and Barriovuevo, G. 1992. Isolated NMDA receptor-mediated synaptic responses express both LTP and LTD. $J$. Neurophysiol. 67: 1009-10013.

Received August 22, 2005; accepted in revised form December 20, 2005. 


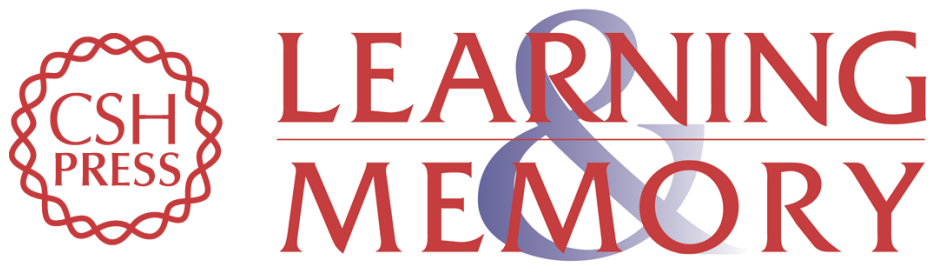

\section{Dopamine transporter blockade increases LTP in the CA1 region of the rat hippocampus via activation of the D3 dopamine receptor}

Jarod Swant and John J. Wagner

Learn. Mem. 2006, 13:

Access the most recent version at doi:10.1101/lm.63806

References This article cites 28 articles, 6 of which can be accessed free at:

http://learnmem.cshlp.org/content/13/2/161.full.html\#ref-list-1

License

Email Alerting Receive free email alerts when new articles cite this article - sign up in the box at the Service top right corner of the article or click here. 